\title{
Los retos de la planificación territorial orientada a la conservación y mejora del paisaje. Caso del Plan Especial del Yermo (Álava)
}

\author{
Miravalles, O. ${ }^{*}$, Díaz, J.2 , Zúñiga, I. ${ }^{3}$ \\ ${ }^{1}$ Oscar Miravalles Quesada, C/ Grupo Villanueva 10, C.P.: 48920 Portugalete (Bizkaia). \\ ${ }^{2}$ Jaime Díaz Morlán, Sagrada Familia 3, esc.3, 7º A, C.P.: 50012 Zaragoza (Zaragoza). \\ ${ }^{3}$ Irene Zúñiga Sagredo, P.de Cervantes, 7-A, 2ºcha, C.P.: 01007 Vitoria-Gasteiz (Álava). \\ *Autor para correspondencia: oscarmiravalles@yahoo.es
}

\section{Resumen}

El Plan Especial de Protección y Conservación de Santa María del Yermo en Llodio propone preservar el conjunto monumental de este santuario alavés articulándolo con un entorno de cerca de 433 Ha. que posee evidentes valores culturales y naturales. El fuerte vínculo afectivo de los vecinos con este enclave fue el factor decisivo que animó al Ayuntamiento a impulsar el Plan Especial superando las trabas de un PGOU que ya se entendía obsoleto y en el que primaban criterios productivos. Mantener los paisajes tradicionales que la sociedad en general percibe como agradables resulta complejo cuando cesan los usos que los propiciaron. Esta interrupción supone la ruptura del equilibrio que generó aquel paisaje y pone en marcha nuevas dinámicas. La mejora del bosque autóctono que el Plan propone, permite lograr un aumento de los servicios ecosistémicos, aunque supone la disminución del rendimiento económico basado en los aprovechamientos forestales intensivos precedentes. Las dificultades aumentan si en lugar de montes públicos se trata de suelos privados. Este escrito resume las estrategias con las que se dota al Plan para ser usado como herramienta para la protección y transformación del paisaje y analiza los resultados obtenidos en sus dos primeros años de andadura. Las conclusiones pretenden ayudar en una toma de decisiones futura reflexionando sobre algunas cuestiones clave que afectan al diseño de los Planes Especiales de Protección y Conservación.

Palabras clave: Área protegida, aprovechamientos forestales, restauración ambiental. 


\section{Introducción}

Contexto. El Santuario de Santa $\mathrm{M}^{\mathrm{a}}$ del Yermo y la Ermita de Santa Lucía constituyen un conjunto monumental con alto valor patrimonial y cultural inscrito como Bien Cultural, con la categoría de Conjunto Monumental, en el Inventario General del Patrimonio Cultural Vasco (Orden de 2 de diciembre de 2002). Está enclavado en una zona de media montaña de la comarca Cantábrica Alavesa, en el término municipal de Llodio. Todo su entorno posee vocación de terreno forestal arbolado, intercalado con zonas de campiña atlántica junto a varios núcleos rurales y unos pocos caseríos dispersos. Predominan en el espacio las masas productoras de coníferas con unos pocos retazos de bosque autóctono, entre los que destaca el encinar del Yermo.

Usos obsoletos y paisajes deseados. La presencia humana en este lugar, reflejada a través del patrimonio histórico heredado, ha establecido en cada época una relación con el entorno natural basada en el aprovechamiento de sus recursos y su explotación, dando como resultado un paisaje humanizado. Desde el abandono generalizado del caserío vasco a mediados del siglo XX y con la extensión de las masas forestales de especies de crecimiento rápido (Michel y Gil, 2013), la imagen idealizada de paisajes deseados por la población, especialmente la urbana, se ha ido alejando de la realidad del territorio (Askasibar, 2007).

Necesidad de recuperación. En este contexto, un enclave tan singular como el Yermo y su entorno han llegado a alcanzar un estado de cierto abandono, degradación y olvido, surgiendo la necesidad de cambiar esa tendencia y de recuperar sus valores (Fig. 1).

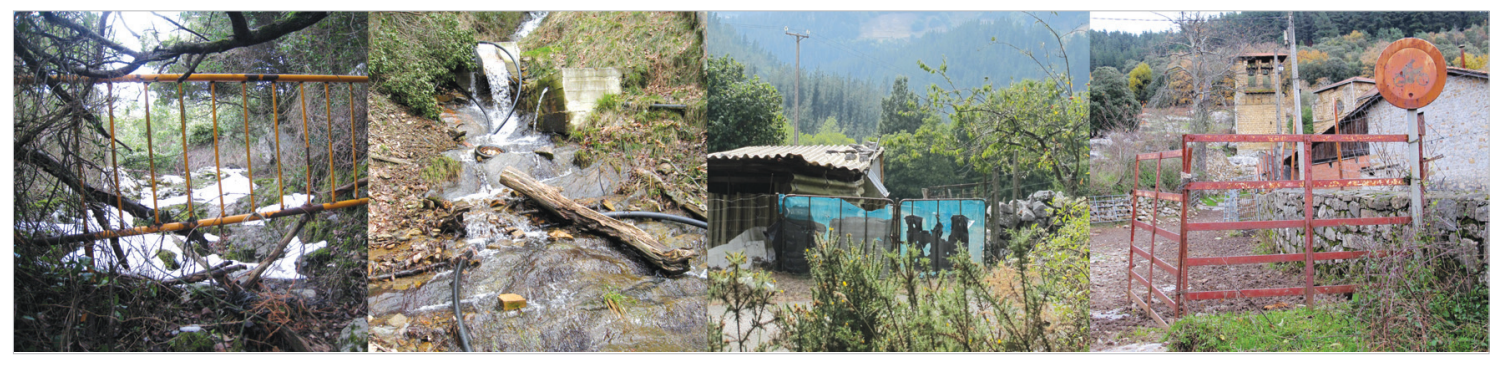

Figura 1. Diversas imágenes del Yermo y su entorno natural que muestran aspectos de su degradación: escombros, captaciones irregulares en arroyos, construcciones ilegales y deterioro del patrimonio por la actividad ganadera descontrolada.

Herramienta: el Plan Especial. Es entonces cuando el Ayuntamiento de Llodio establece el Plan Especial de Protección y Conservación como la herramienta necesaria para frenar ese deterioro y regular todos los usos vigentes o futuros que pueda albergar el espacio, persiguiendo así revitalizar el Yermo. El fuerte vínculo y el especial cariño que sienten los vecinos hacia este lugar, es otro motivo más que 
obliga e impulsa de manera decidida la puesta en marcha del trabajo, que se inicia en octubre de 2012 .

Valoración de la efectividad del Plan. Mediante la redacción de este Plan, así como de otros trabajos similares donde el binomio cultural-natural es fundamental, se nos plantea como objetivo el reto de compatibilizar diferentes usos e intereses sobre el territorio que a veces entran en conflicto, como son la ganadería y lo forestal, la caza y el recreo, la conservación y la accesibilidad o los nuevos usos. También nos vemos obligados a cuestionar la efectividad de la recuperación del paisaje mediante la herramienta que constituyen los planes especiales. ¿Habrá mejorado realmente la situación de ese patrimonio tras nuestra labor?

Este texto pretende analizar estas cuestiones una vez transcurridos los dos primeros años de andadura del Plan Especial del Yermo y valorar los resultados obtenidos.

\section{El Plan Especial del Yermo, claves generales}

\subsection{La primera decisión: el ámbito de actuación del Plan}

La propuesta del concurso supuso una apuesta radical al ampliar el ámbito inicialmente previsto para el Plan Especial que partía de una delimitación marcada por el Plan General de Ordenación Urbana de Llodio, vigente desde 1997. Se planteó una nueva delimitación para el Plan que realmente conformara una misma unidad cultural y paisajística, y en el que se recogieran sus principales valores patrimoniales y naturales. Para corregir la zonificación anterior fue necesario realizar una modificación puntual del Plan General que quedó justificada gracias a la alineación del nuevo planteamiento con la normativa de rango superior (Directrices de Ordenación Territorial, Norma Foral de Montes, PTS Agroforestal, PTS de márgenes de ríos y arroyos y PTP del área funcional de Llodio, fundamentalmente). De esta manera, y con el apoyo de una red de corredores con capacidad para recuperar el funcionamiento ecológico del territorio, se sentaron las bases para la recuperación de su paisaje natural.

Partiendo del área interior que rodea al Santuario, que caracteriza y da sentido a la actuación, se añadieron los sectores periféricos buscando una continuidad hasta lograr un área coherente de $433 \mathrm{Ha}$.

Los criterios para esta delimitación fueron los siguientes:

- Agrupación de elementos patrimoniales dispersos.

- Integración de terrenos de propiedad municipal o en trámite de adquisición.

- Concatenación de unidades paisajísticas coherentes.

- Agrupación de cuencas visuales de interés para la unidad de la zona del santuario. 


\subsection{El análisis del territorio y la participación ciudadana}

El conocimiento profundo de los valores del territorio es imprescindible para una toma de decisiones acertada en la planificación. Conocer su origen, contrastar su originalidad o excepcionalidad a distintas escalas geográficas y entender su funcionamiento, así como el grado de deterioro actual, eran cuestiones que debían estar resueltas antes de comenzar cualquier tipo de ordenación o regulación.

Para ello se obtuvo la información a dos niveles:

- Mediante el estudio técnico del lugar, que incluye el reconocimiento a pie de campo, entrevistas personales, el estudio de la normativa vigente, de los valores naturales, etnográficos y culturales, los modos de vida de los núcleos habitados, la población y las actividades económicas asociadas, etc. En esta fase se detecta la cantidad de elementos sobre los que falta conocimiento e investigación suficiente.

- A través de la participación ciudadana, un proceso abierto a todos los grupos interesados: forestales, ganaderos, vecinos, cazadores, excursionistas, técnicos municipales, técnicos de otras administraciones, responsables religiosos del santuario, etc. Además de la participación activa de estos colectivos, se contó con la opinión de diversos expertos externos. De esta forma, las aportaciones recabadas, no sólo fueron decisivas para completar el conocimiento del lugar (imaginación colectiva, memoria, tradiciones, religión, recuerdos, trabajo, vida cotidiana en el lugar, etc.), sino también para conocer la imagen final deseada por los ciudadanos para el futuro del Yermo.

De esta manera, el análisis del lugar, junto al proceso de participación realizado en varias fases, y el criterio de los técnicos municipales, resultó ser una combinación muy útil para reunir el conocimiento suficiente y así validar la propuesta técnica.

\subsection{La conservación del patrimonio cultural}

El núcleo del que parte la necesidad de protección del espacio es inicialmente un elemento patrimonial, cultural y religioso, un Santuario. Su ubicación en el paisaje no es casual y es el origen de muchos otros elementos a proteger, como son los núcleos habitados, caminos tradicionales, vía crucis, pozos de nieve, fuentes, etc. Al conocer la historia de estas construcciones y de las sociedades que las ejecutaron estaremos reconociendo el valor simbólico de cada edificio o estructura, y esa importancia se convertirá en el motor de su futura conservación.

\subsection{El equilibrio del medio natural}

Con objeto de planificar su conservación y mejora, se comienza por realizar 
una caracterización del territorio basada en criterios ecológicos y selvícolas, estableciendo una zonificación que en ocasiones llega hasta el nivel de rodal. Esto permite fijar objetivos concretos para cada zona, establecer prioridades de conservación e incluso ritmos de transformación distintos en función de los valores de cada masa. El objetivo es alcanzar un equilibrio en el espacio para que pueda seguir albergando usos productivos (forestales, ganadería, etc.), al mismo tiempo que se mejora la biodiversidad y se amplía el bosque autóctono en determinadas zonas para diversificar y mejorar los servicios ecosistémicos aportados.

\subsection{El proceso de investigación, respuestas basadas en el conocimiento}

La degradación de ecosistemas como el del Yermo raramente puede revertirse sin acciones que aborden los efectos negativos o refuercen los efectos positivos de una o más de las variables que producen el cambio (VV.AA., 2015). Para asegurar la gestión sostenible de este ecosistema, es imprescindible aumentar el conocimiento e información sobre él, y utilizar el que ya existe. Por ello el proceso de investigación del medio natural y cultural se incluye como una acción más a llevar a cabo durante la ejecución del Plan.

Los estudios botánicos, los informes sobre la biodiversidad o la investigación histórica aplicada a la rehabilitación de la edificación, son algunos de los trabajos considerados fundamentales.

Una vez delimitado el ámbito y obtenidos los datos sobre él, los tres pilares básicos sobre los que se apoya el Plan Especial para recuperar y potenciar el área del Yermo son: conservar el valor de su patrimonio cultural, alcanzar un adecuado equilibrio del medio natural y continuar mejorando el conocimiento del medio natural y cultural.

\section{EI Plan como herramienta para la protección del paisaje}

El Plan Especial concreta una serie de estrategias y acciones encaminadas específicamente a mejorar el paisaje:

Zonificación pormenorizada y red de corredores. Es la base para establecer una protección diferenciada y queda establecida de la siguiente manera (Fig. 2):

- Zona de Especial Protección: Zonas de Reserva (encinar y bortal), Zonas de Protección de Aguas Superficiales (arroyos y barrancos), Zonas de Protección Activa (cordal y rodales singulares) y Zonas de Progresión Ecológica - Grado 1 (corredores ecológicos a transformar en corto o medio plazo) (Fig. 3).

— Zona de Mejora Ambiental: Zonas de Conservación Activa (rodales con vestigios de usos tradicionales para uso didáctico), Zonas de Progresión Ecológica - Grado 2 (transformación a largo plazo) (Fig. 4). 


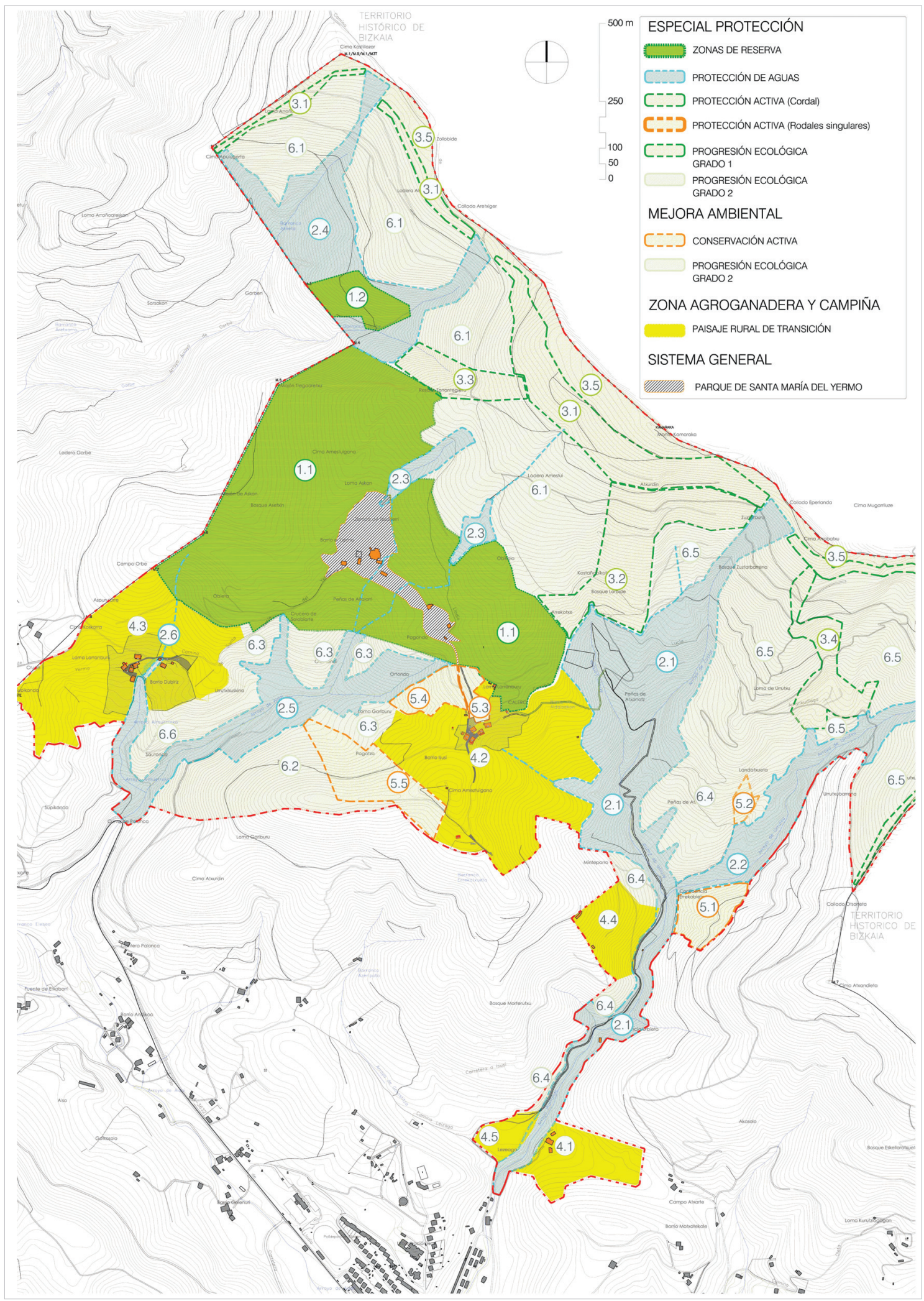

Figura 2. Representación del ámbito del Plan Especial y su zonificación. (Fuente: doc. Plan Especial del Yermo. Autores: Bárcena, Díaz Morlán, Miravalles y Zúñiga). 


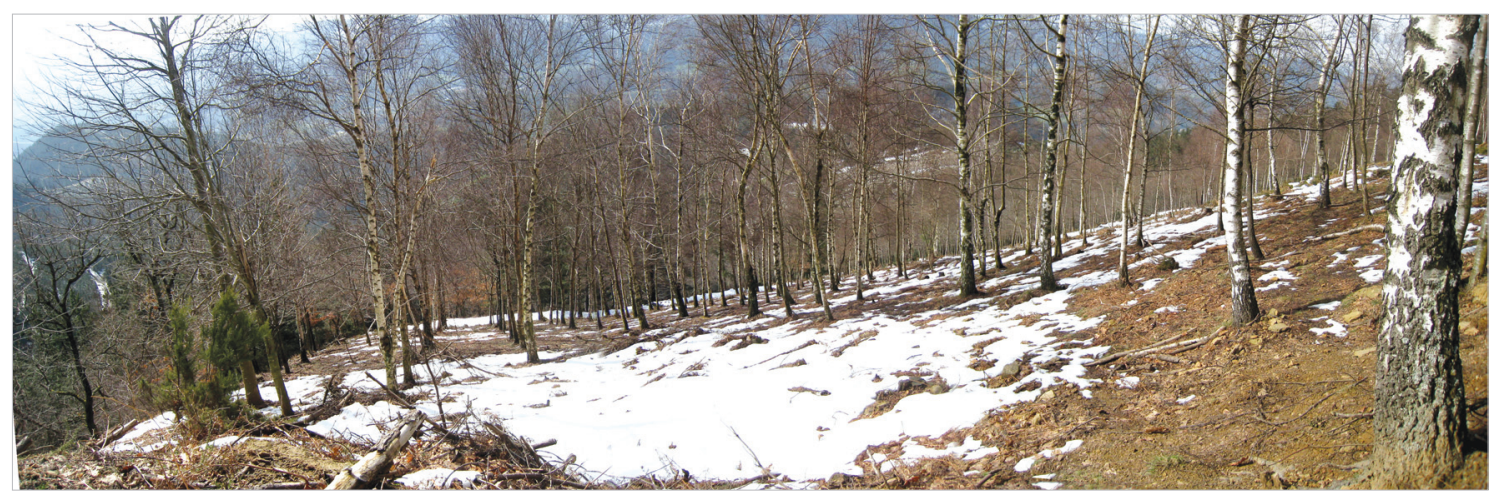

Figura 3. Rodal de abedul (Betula alba) en el paraje de Susteburu, destinado a conectar masas naturales de interés ecológico mediante su ampliación (Zonas de Progresión Ecológica - Grado 1 del Plan Especial del Yermo).

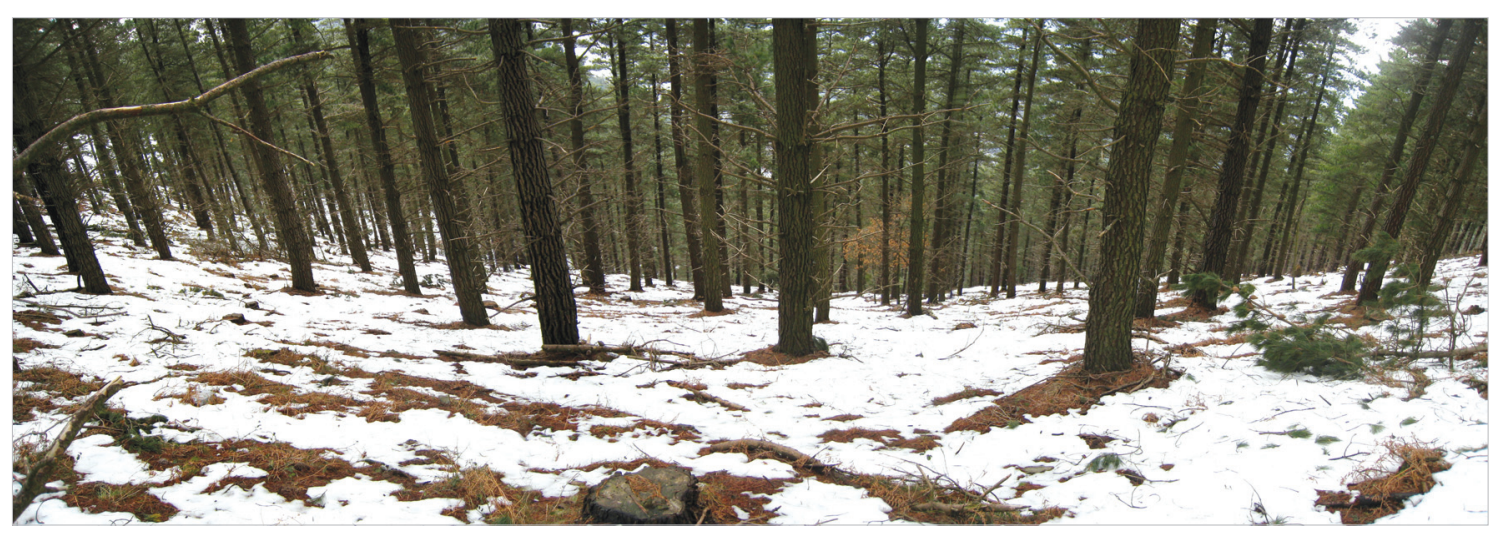

Figura 4. Masas de pino insigne (Pinus radiata) en las laderas del Kamaraka, a transformar a medio plazo mediante la plantación del $30 \%$ de frondosas autóctonas después de cada corta final (Zonas de Progresión Ecológica - Grado 2 del Plan Especial del Yermo).

- Zona Agroganadera y Campiña: núcleos habitados y campas, donde se fomentarán los usos agroganaderos y residenciales vinculados.

- Sistema general: Parque del Yermo, donde se concentran los principales usos públicos, tales como religiosos, culturales, turísticos y recreativos.

De esta forma quedan establecidas las prioridades de conservación y la red hidrográfica sirve como base principal para establecer una red de corredores ecológicos internos que articule el espacio. Esta red da continuidad a la Red de Corredores de la Comunidad Autónoma de Euskadi, al estar englobado parte del ámbito del Plan Especial en el área núcleo del Ganekogorta, una zona que presenta Especial Protección según las Directrices de Ordenación del Territorio del País Vasco (Fig.5).

Regulación de la ganadería y el pastoreo: Como origen de múltiples conflic- 


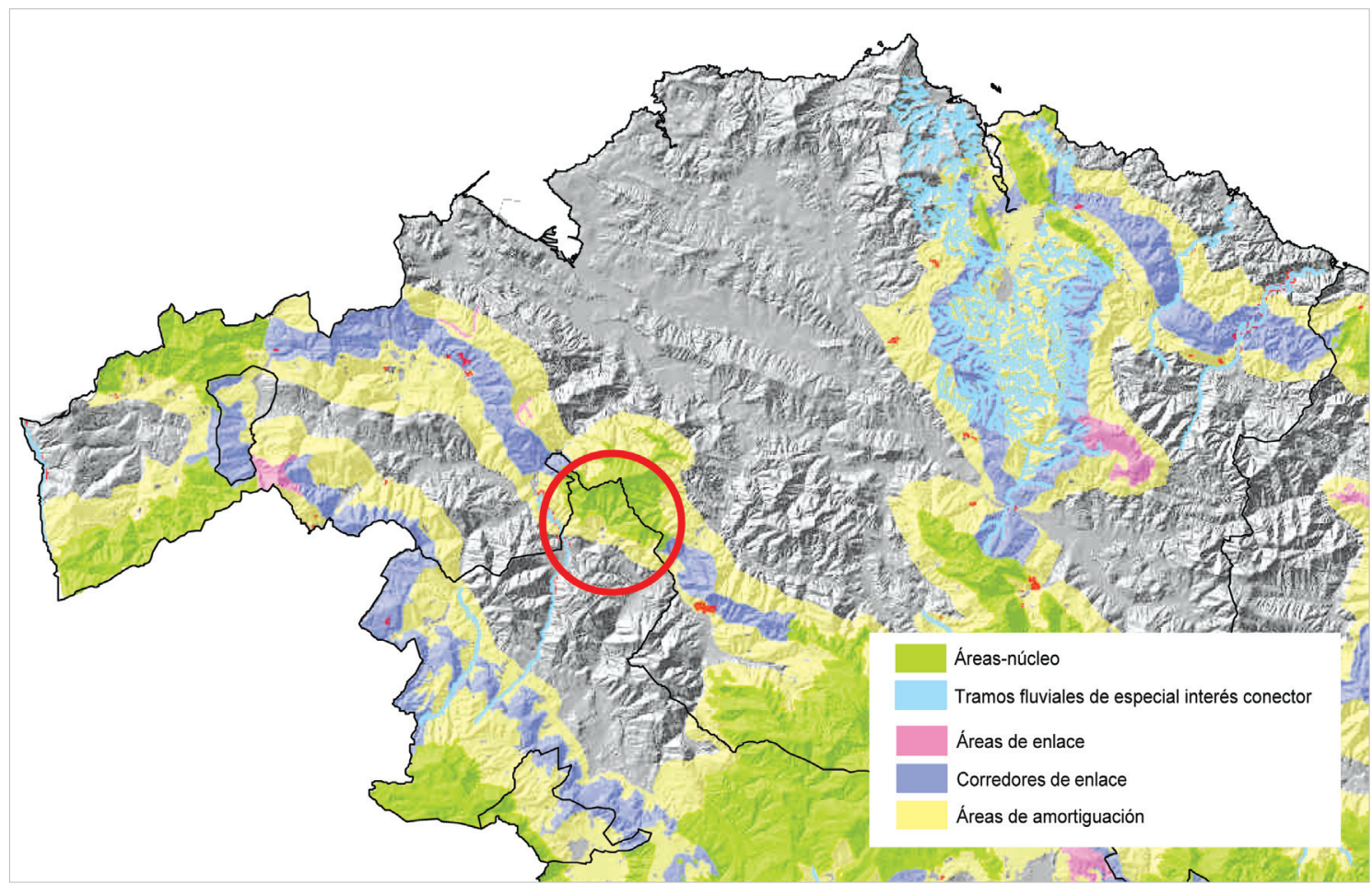

Figura 5. Localización del área del Yermo en relación al área núcleo del Ganekogorta. (Fuente: Mapa 7 del documento Red de corredores ecológicos de la CAPV, Gobierno Vasco, enero 2005).

tos y deterioro del entorno del Yermo, se propone hacer cumplir estrictamente la normativa vigente, estudiando las cargas ganaderas admisibles en cada terreno, prohibiendo este uso en zonas sensibles (cauces de agua y manantiales, zonas acotadas para la regeneración del bosque y reservas botánicas integrales) y evitando el pisoteo continuo de las mismas zonas. Se permite especialmente el pastoreo de ganado ovino o caballar en las campas del entorno del Santuario del Yermo para mantener el equilibrio del paisaje actual.

Plan de gestión: Estas aspiraciones de protección y conservación, por muy adecuadas o demandadas que sean por la sociedad, no se harán efectivas sin un plan de gestión que posibilite su puesta en marcha. En la configuración de dicho plan cabe fijarse en dos modelos:

- Modelo autosuficiente: básicamente el que ha funcionado hasta la fecha en el Yermo. Los recursos son explotados por sus dueños sin otro condicionante que el marco legislativo común al resto del territorio. Se obtienen beneficios económicos y el paisaje es el resultado más o menos libre de dicha explotación.

- Modelo subvencionado: comúnmente planteado en los Espacios Naturales Protegidos. La inversión exterior consigue mantener los recursos 
naturales y culturales en un estado de conservación alineado con objetivos que no son puramente económicos. Los beneficios son de orden social o medioambiental y el paisaje es buscado o pretendido.

Siendo conscientes del necesario equilibrio entre los objetivos conservacionistas y la realidad socioeconómica que ha propiciado los valores del paisaje que pretendemos potenciar, el Plan se acoge a un modelo mixto que permita, si no "explotar conservando", al menos sí "conservar explotando". El matiz es importante porque define el límite de la permisividad normativa sobre las explotaciones agroforestales y ganaderas y el uso social del territorio objeto de protección. Este modelo intenta hacer compatible la explotación privada de los recursos con una inversión pública que posibilite el cambio de dirección del área. La Tabla 1 muestra el orden de magnitud del plan de inversiones óptimo incluido en el Plan Especial.

Tabla 1. Calendario de inversiones incluido en el documento de Gestión del Plan Especial aprobado.

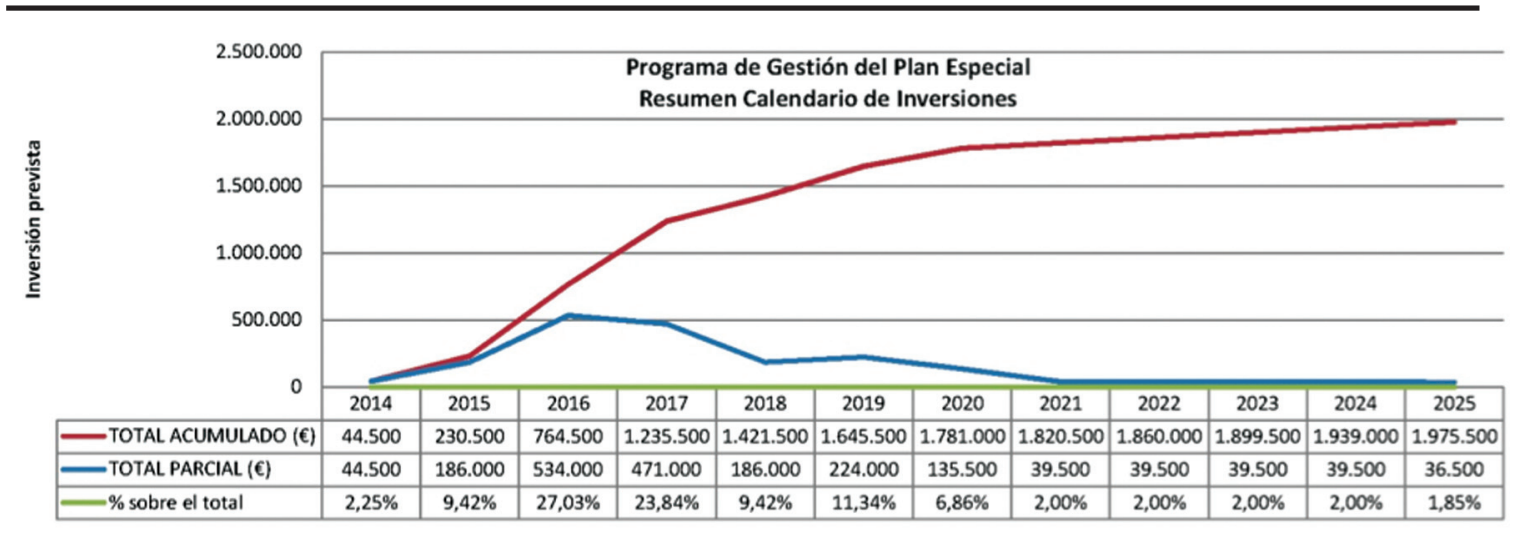

Tipos de actuaciones. En concreto, la ejecución del Plan Especial se desarrolla en base a seis tipos de actuaciones:

1 - Redacción de estudios.

2 - Redacción de proyectos y planes.

3 - Obras / Aprovechamientos.

4 - Trámites administrativos.

5 - Acciones de promoción.

6 - Asuntos de promoción privada.

Se diseña así el camino hacia la recuperación del área, y con ella la de su paisaje, pero no se renuncia a una evolución más ambiciosa que logre vincular la zona a posibles figuras de protección como un Espacio de la Red Natura 2000, un Parque Natural, un Parque Cultural o la declaración de Paisaje Singular. Se aspi- 
ra a recuperar el papel de foco de atracción para un público más amplio que incluye a los miles de potenciales usuarios del entorno de Bilbao. Este escenario justificaría la creación de un centro de estudios medioambientales o de tratamientos forestales. La degradación del patrimonio cultural y natural por el contrario, sería una irreparable pérdida que acabaría con la ligazón que aún nos une con nuestro territorio.

\section{Resultados de la aplicación del Plan}

El tiempo transcurrido desde la aprobación definitiva del Plan (Julio 2015) no es suficiente para plantear un análisis de las mejoras medioambientales alcanzadas por su aplicación. La mayoría de los objetivos medioambientales requieren para su evaluación periodos más largos y estudios de campo con datos contrastables con los que se están recopilando en estos momentos iniciales.

No pretendemos tampoco plantear un ejercicio de economía ambiental puesto que no creemos que resulten útiles aquí análisis coste-beneficio al estilo de los propuestos por autores involucrados en la valoración de los servicios ambientales (VV.AA., 2010). No existe un límite para la evaluación de los impactos económicos favorables ni para la de los servicios ecosistémicos que el área presta, por lo que es difícil buscar en ese camino una razón que justifique la inversión propuesta.

Los resultados que pretendemos evaluar son los referentes a los avances en las acciones enfocadas a proteger los valores medioambientales y culturales del sector. Recopilamos para ello la información de la actividad desarrollada en el periodo 20142016 (Tab. 2) y comparamos estos datos con lo que se planteaba para el desarrollo del Plan en su documento de Gestión, expresado en la memoria y en los objetivos económicos de inversión (Tab. 1).

- Resultados sobre la inversión prevista para la gestión del Plan:

- Hasta este año 2016 se ha realizado el 31\% de la inversión económica prevista como escenario ideal en el documento de Gestión del Plan (Tab. 1 y 2), lo que supone un resultado aceptable teniendo en cuenta la situación económica global y el corto periodo de tiempo transcurrido desde la aprobación definitiva del Plan.

- Resultados sobre objetivos comunes o de gestión:

- Constitución reciente de la Comisión de Seguimiento del Yermo como modo de asegurar una gestión alineada con el Plan y consensuada entre todos los agentes. Recordemos que entre sus funciones están la captación de recursos, el articular el desarrollo del programa, el control y la gestión de los terrenos y bienes inmuebles incorporados a la red municipal y el velar por el control del cumplimiento de la metodología y la normativa. Es decir, sin Comisión no habría una acción ordenada y su constitución supone un gran avance. 
Tabla 1. Acciones realizadas desde la aprobación del Plan Especial hasta Mayo del 2016.

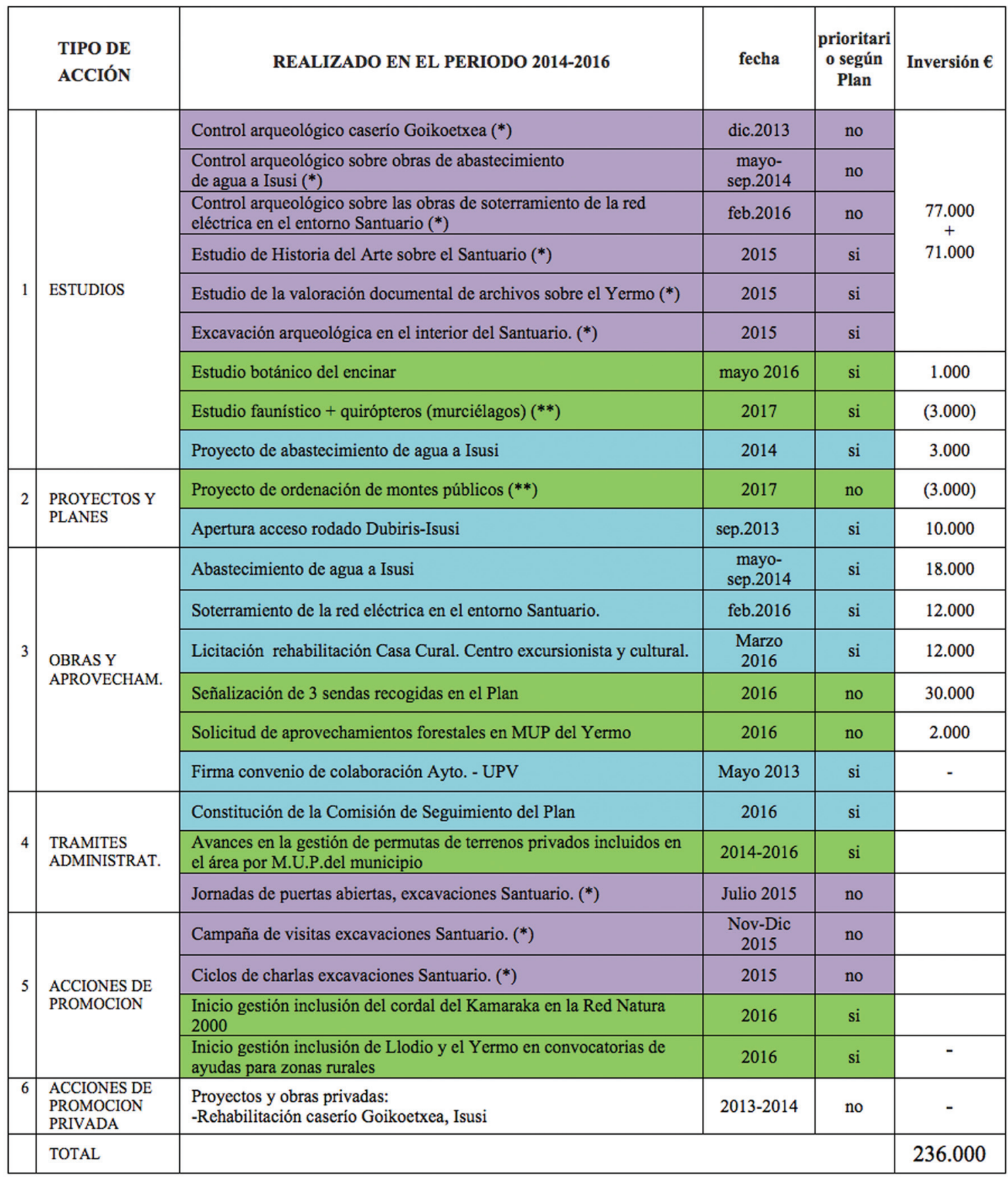

(*) Trabajos vinculados a la subvención del " $1 \%$ cultural" cofinanciada por el Gobierno Vasco y el propio Ayto. de Llodio dotada con $77.000 €$ para el periodo 2014-2015 y de 71.000 € para el 2015-2017. En ambas ocasiones la iniciativa de las gestiones ha estado a cargo del arqueólogo de la UPV miembro de la Comisión del Yermo y promotor y director de las excavaciones en el sector.

$\left.{ }^{(* *}\right)$ Trabajos cuya ejecución está ya acordada y tienen fecha de inicio inminente 
- Firma del convenio de colaboración Ayto-UPV en Mayo del 2013 según se preveía en el Plan como actuación estructural. Ha propiciado el escenario necesario para que surjan iniciativas de investigación promovidas por agentes muy concretos.

- Ejecución de obras de infraestructuras. El abastecimiento de aguas a Isusi y el soterramiento de la red eléctrica eran obras previstas con anterioridad a la redacción del Plan y se recogían en él. Aun siendo prioritarias, el modo de ejecutarlo a través de la apertura de una nueva pista forestal que arrasó el camino tradicional de Dubiris al Yermo no fue adecuado. El resultado queda empañado así por una ejecución no conforme al Plan.

- Resultados sobre objetivos culturales:

- Actividades arqueológicas y de divulgación. Es un gran avance que el Convenio de Colaboración con la UPV haya desencadenado el inicio de la actividad de investigación. El área arqueológica se ha desarrollado en el modo deseado en torno al núcleo del Santuario y presenta un futuro esperanzado al menos hasta el 2017. Se puede considerar un éxito dentro del clima de incertidumbre creado por la coyuntura de crisis económica.

- Resultados sobre objetivos medioambientales:

- Actividades de estudio: Si tal como se espera se inician los estudios botánicos en mayo del 2016 y los faunísticos al siguiente año, se habrán sentado las bases para el correcto desarrollo de los objetivos del Plan.

- La redacción del proyecto de ordenación de montes públicos de Llodio prevista para 2017 constituiría un gran avance para el área debido a la facilidad de gestión forestal que conllevaría.

- Las acciones medioambientales recopiladas en la Tabla 2 siguen las prioridades establecidas en la planificación y están alineadas con los objetivos principales. El ritmo de inversión es más lento que el previsto, pero se avanza en la dirección adecuada. En concreto, las gestiones para solicitar la inclusión del cordal del Kamaraka en la Red Natura 2000, darían como resultado el acceso a nuevas fuentes de financiación que permitirían incidir sobre la mejora del paisaje natural del Yermo.

\section{Conclusiones}

\subsection{En cuanto a los resultados}

1. El funcionamiento del Plan parece depender de la existencia de una serie de elementos concatenados que forman un "círculo virtuoso" entre los que se encuentran: la voluntad vecinal, el impulso político, la redacción y aprobación del propio Plan, agentes individuales que lo estimulan, estudios científicos en los que apoyarse, etc. El factor económico es por supuesto impor- 
tante, pero no asegura el éxito a priori sino que aparece cuando el resto de elementos están ya presentes.

2. El papel jugado por actores muy concretos como han sido los técnicos municipales responsables del patrimonio y del medio forestal o el arqueólogo de la UPV, se demuestra decisivo para el desarrollo del Plan. Sin su decidido impulso poco o nada de lo realizado hasta la fecha hubiera sido posible. Identificar a estas personas clave y potenciar y facilitar su labor es una prioridad para cualquier Plan.

3. Es habitual hacer referencia a la fragilidad de un modelo basado en las subvenciones en una coyuntura de crisis económica puesto que sin inversión pública no es posible implantar las acciones de mejora previstas. Pero al mismo tiempo esa misma crisis es la que, al restar atractivo al negocio forestal, facilita la implantación del cambio que la sociedad demanda para el área. Parece entonces que no es tanto un problema del modelo económico implantado como del perfil del propietario, la mentalidad de la sociedad y la intención política que canaliza sus aspiraciones.

4. El municipio posee una capacidad limitada en medios técnicos y recursos económicos para la gestión de un patrimonio forestal que es extenso y productivo. Esta realidad nos plantea la posibilidad de modificar los tratamientos forestales previstos en el Plan ampliando los plazos para la transformación de ciertas masas forestales, o bien realizando un cambio más progresivo.

\subsection{En cuanto al proceso}

1. Los efectos ambientales de las masas monoespecíficas de pino insigne o radiata (Pinus radiata) están en discusión prácticamente desde el inicio de la introducción de la especie en el País Vasco. A dichos efectos hay que sumar los de procesos geoecológicos debidos al manejo de la corta a hecho de las masas (Ainz y González, 2008). Sin embargo, esta visión ambientalmente negativa contrasta con los enunciados de otros estudios que atestiguan el avance de la vegetación potencial bajo el dosel de las masas de estas coníferas en zonas similares de Bizkaia (Onaindia et al., 2013) tal y como comprobamos en los rodales de pino del sector del Yermo pasados de turno. Según esta visión el tiempo no corre en nuestra contra, como ocurre con el deterioro del patrimonio edificado, sino que se avanza hacia otro escenario no necesariamente peor que el anterior. Parece entonces que la Naturaleza se impone sobre las eventuales crisis del sector forestal poniendo la reserva genética de su vegetación potencial a disposición de una recuperación ambiental a largo plazo, aunque en ocasiones pueda necesitar apoyos puntuales para diversificar esos recursos genéticos o acelerar el proceso.

2. Los criterios medioambientales de la normativa concerniente a la Ordenación Territorial en el País Vasco son más ambiciosos que los planteamien- 
tos de muchos Planes Generales en vigor cuya ordenación afecta al suelo no urbanizable del municipio. En esos casos, las D.O.T, los diferentes Planes Sectoriales o el propio Catálogo de Paisajes de Álava son herramientas eficaces a disposición del redactor para solventar el escollo de la normativa municipal, aunque sea a costa de una modificación puntual del P.G.O.U.

3. El cese de la actividad humana sobre los espacios naturales produce el deterioro de su patrimonio cultural por abandono pero puede ocasionar una mejora ambiental con la disminución de la presión de explotación sobre los recursos. Los Planes Especiales deben enfrentarse a esta aparente contradicción gestionando todas las variables para encontrar el equilibrio necesario que resuelva la encrucijada.

4. Aunque los primeros pasos tras la aprobación fueron inciertos, consideramos que se dio un punto de inflexión con el logro de las primeras subvenciones y el inicio de las actuaciones arqueológicas. Desde entonces se ha implantado la tendencia de la observación del cumplimiento del Plan en un ambiente de cierta confianza hacia el mismo.

\section{Bibliografía}

\section{LIBROS Y ARTÍCULOS}

Ainz, M.J. y González, M.J., 2008. Gestión de montes en la reserva de la biosfera de Urdaibai: una oportunidad perdida, Boletín de la A.G.E. N. ${ }^{\circ}$ 46, pp 330-333

Askasibar, M. 2007. La evolución e idealización del paisaje vasco. Geografía simbólica. Cultura de los espacios, Lasarte-Oria. Ed. Etor, 8-19.

Loidi, J.J., 2007. La evolución del paisaje vegetal del centro-norte de la Península Ibérica a lo largo de la historia. Suplemento 11-B del Boletín de la R.S.B.A.P. Real Sociedad Bascongada de los Amigos del País, Bilbao.

Michel, M.; Gil, L. 2013. La transformación histórica del paisaje forestal en la Comunidad Autónoma de Euskadi. Gobierno Vasco, Vitoria-Gasteiz.

Onaindia, M., Ametzaga-Arregi, I., San Sebastián, M., Mitxelena, A., Rodríguez-Loinaz, G., Peña, L., G. Alday, J. 2013. Can understorey native woodland plant species regenerate under exotic pine plantations using natural succession? Forest Ecology and Management 308: 136-144.

VV.AA, 2005, Evaluación de los Ecosistemas del Milenio Informe de Síntesis, millenniumassessment.org, EM, p. 28

VV.AA., 2010. Servicios Ambientales en Reservas de la Biosfera Españolas. Miren Onaindía Olalde. (ed.), OAPN, Madrid.

\section{NORMATIVA CITADA EN EL TEXTO}

- Proyecto de modificación $\left(40^{\mathrm{a}}\right)$ del Plan General de Ordenación Urbana de Llodio y Plan Especial de Protección y Conservación del conjunto monumental de Santa María del Yermo y ermita de Santa Lucía, aprobación Ayto. Llodio 20 Julio 2015. 
— Modificación de las D.O.T. por ORDEN de 24 de febrero de 2012.

- Plan Territorial Sectorial (P.T.S.) Agroforestal, aprobación prov. Gob. Vasco, Orden de 8 de Noviembre de 2010.

- Norma Foral de Montes, aprobada por las Juntas Generales de Álava, no 11/2007, de 26 de marzo.

— Red de corredores ecológicos de la CAPV. Gobierno Vasco 2005.

- Plan Territorial Parcial (P.T.P.) del área funcional de Llodio, aprobación Gob. Vasco, Decreto 25 enero 2004.

- ORDEN de 4 de diciembre de 2002, de la Consejera de Cultura, por la que se inscribe el Santuario de Nuestra Señora del Yermo en Llodio (Araba) como Bien Cultural, con la categoría de Conjunto Monumental, en el Inventario General del Patrimonio Cultural Vasco.

- Plan Territorial Sectorial (P.T.S.) de Ordenación de Márgenes de los Ríos y Arroyos de la Comunidad Autónoma del País Vasco (Vertiente Cantábrica). Aprobación Gob. Vasco, DECRETO 415/1998, de 22 de diciembre.

- Directrices de Ordenación del Territorio del País Vasco (D.O.T.) Aprobadas por el Gob. Vasco en 1997 por el Decreto 28/1997, de 11 de febrero. 
